Ambiguous Citizenship in an Age of Global Migration 
Line.

A trace.

Understanding a space.

Our relationship,

Mapping.

Putting ourselves into context,

By which we measure ourselves,

Time.

Repeating.

Process. Material. Marks.

Priya Chohan ${ }^{1}$

Citizenship . . . is a more confounding concept than most who employ the word usually recognize.

Linda Bosniak ${ }^{2}$

1 (C) Priya Chohan, untitled and undated poem.

2 Linda Bosniak, The Citizen and the Alien: Dilemmas of Contemporary Membership (Princeton, NJ: Princeton University Press, 2006), p. 1. 


\title{
Ambiguous Citizenship in an Age of Global Migration
}

\author{
Aoileann Ní Mhurchú
}


(C) Aoileann Ní Mhurchú, 2014

Edinburgh University Press Ltd

The Tun - Holyrood Road

12 (2f) Jackson's Entry

Edinburgh EH8 8PJ

www.euppublishing.com

Typeset in 11/14 Sabon by

Servis Filmsetting Ltd, Stockport, Cheshire and printed and bound in Great Britain by

CPI Group (UK) Ltd, Croydon CR0 4YY

A CIP record for this book is available from the British Library

ISBN 9780748692774 (hardback)

ISBN 9780748692781 (webready PDF)

The right of Aoileann Ní Mhurchú to be identified as author of this work has been asserted in accordance with the Copyright, Designs and Patents Act 1988 and the Copyright and Related Rights Regulations 2003 (SI No. 2498). 